\title{
Non-Obese Cushing's Syndrome in an Aged Woman with Non-Insulin-Dependent Diabetes Mellitus
}

\author{
Kenzo Uchida, Ryoji Iwasaki, Shigeru Nakano, Toshikazu Kigoshi, \\ Shinpei Morimoto and Hisao Matsunou*
}

\begin{abstract}
A 76-year-old diabetic woman with non-obese Cushing's syndrome developed poor glycemic control with glibenclamide. She presented with a slight weight loss while bedridden due to a fall. Cushing's syndrome in this patient was suspected because of hypercortisolemia with eosinopenia, and adrenal Cushing's syndrome was diagnosed by endocrine and radiological examinations. A right adrenal adenoma was confirmed by autopsy. In this patient, progressive obesity and other common features of Cushing's syndrome may have been concealed by aging itself and coexisting diabetes mellitus.
\end{abstract}

(Internal Medicine 34: 1089-1092, 1995)

Key words: elderly, no obesity, adrenal adenoma, autopsy

\section{Introduction}

Cushing's syndrome is a cluster of clinical features due to glucocorticoid excess, occurring predominantly in women aged 25 to 45 years $(1,2)$. In this syndrome, progressive obesity, of characteristic fat distribution, is the commonest feature, and the lack of weight gain is unusual unless there is malignant nature $(1,2)$. We describe an aged woman in whom Cushing's syndrome due to an adrenal adenoma developed with no weight gain during the course of diabetes mellitus.

\section{Case Report}

A 76-year-old diabetic woman was admitted to our university hospital, because of poor glycemic control. She had a 16year history of non-insulin-dependent diabetes mellitus (NIDDM) with no obesity and mild hypertension, both of which were treated by her physician. For the previous two to three years, her glycemic control with daily administration of $7.5 \mathrm{mg}$ glibenclamide was poor, showing $\mathrm{HbA}_{1 \mathrm{c}}$ levels of 9.9 to $11.0 \%$. Her blood pressure ranged from $140 / 64-172 / 87 \mathrm{mmHg}$ without any medication. She and her family denied any changes in weight or body habitus, weakness, easy bruising, and hirsutism during the course of her diabetes mellitus. She fell 3 weeks prior to admission, and became bedridden with lumbago and difficulty in walking, and then had slowly progressive dementia with occasional night delirium and a body weight loss of $2 \mathrm{~kg}$.
Her son had diabetes mellitus. Physical examination revealed an expressionless and slender woman $(144 \mathrm{~cm} ; 38 \mathrm{~kg})$ without any appearance of hypercortisolism (Fig. 1). She had the thin skin and generalized muscle weakness of her stated age. Her blood pressure was $138 / 72 \mathrm{mmHg}$, and pulse rate was $78 \mathrm{bpm}$ and regular. Her fundus oculi showed nonproliferative diabetic retinopathy and grade 2 sclerotic changes. The remainder of the physical examination was unremarkable except for a $2 / 6$ systolic ejection murmur at the apex, absent deep tendon reflexes and slight pedal edema.

Laboratory data revealed a hemoglobin level of $122 \mathrm{~g} / \mathrm{l}$, a hematocrit value of 0.40 and a white blood cell count of 8,600 p. $\mathrm{mm}^{3}$ with granulocytosis $(76 \%)$, eosinopenia $(0.4 \%)$ and lymphopenia (16.0\%). Fasting plasma glucose was $20.3 \mathrm{mmol} /$ $l$; immunoreactive $\mathrm{C}$ peptide was $0.7 \mathrm{ng} \mathrm{ml}^{-1}$ (normal, 0.6-2.8) and did not respond to arginine infusion ( $30 \mathrm{~g}$ for 30 minutes). Serum sodium was $147 \mathrm{mmol} / l$, potassium $2.4 \mathrm{mmol} / l$, chloride $100 \mathrm{mmol} / l$, calcium $2.10 \mathrm{mmol} / l$, phosphorus $0.87 \mathrm{mmol} / l$ and bicarbonate $30.1 \mathrm{mmol} / l$. Serum total protein was $59 \mathrm{~g} / \mathrm{l}$, albumin $30 \mathrm{~g} / l$, total cholesterol $4.91 \mathrm{mmol} / l$, triglyceride 1.08 $\mathrm{mmol} / l$, creatinine $80 \mu \mathrm{mol} / l$ and blood urea nitrogen $4.3 \mathrm{mmol} /$ $l$. PRA was $0.14 \mathrm{ng} \cdot l^{-1} \cdot \mathrm{s}^{-1}$, plasma aldosterone $2.5 \mathrm{mmol} / l$ and plasma cortisol $0.81 \mu \mathrm{mol} / l$. Liver function tests were all within normal limits. Arterial gas analysis showed a $\mathrm{pH}$ of 7.48 , an oxygen tension of $11.0 \mathrm{kPa}$ and a carbon dioxide pressure of 5.5 $\mathrm{kPa}$. Urinalysis showed 3+ glucose, negative protein and negative acetone. Electrocardiograms revealed flat $\mathrm{T}$ waves and

From the Division of Endocrinology, Department of Internal Medicine and *the Second Department of Pathology, Kanazawa Medical University, Ishikawa Received for publication January 6, 1995; Accepted for publication July 25, 1995

Reprint requests should be addressed to Dr. Kenzo Uchida, the Division of Endocrinology, Department of Internal Medicine, Kanazawa Medical University, 1-1, Daigaku-cho, Uchinada, Ishikawa 920-02 


\section{UCHIDA et al}

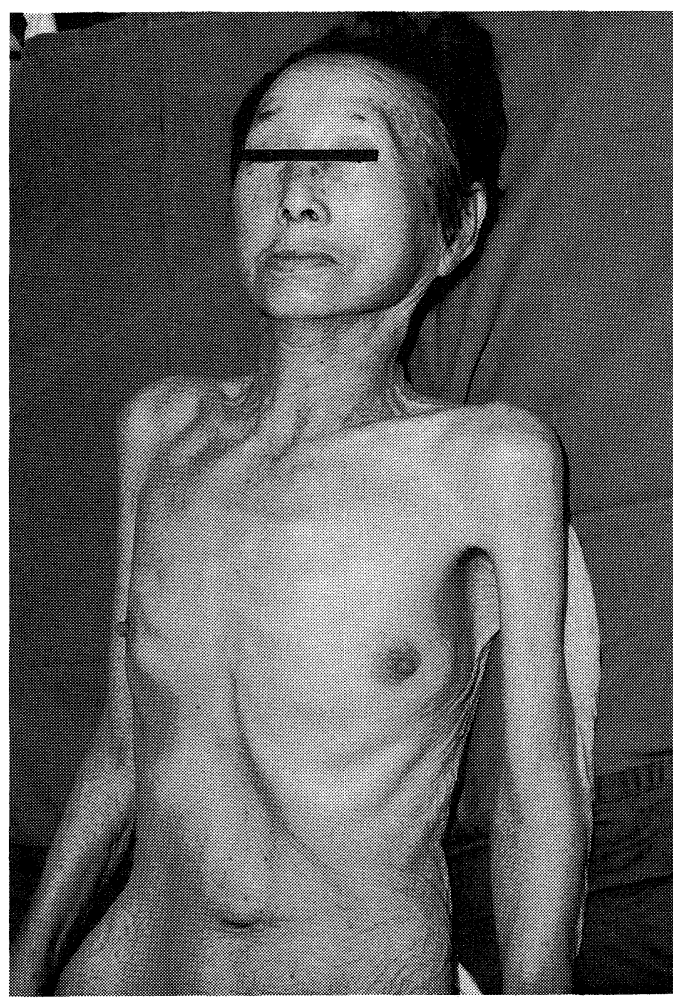

Figure 1. Physical appearance of an aged woman with non-insulin-dependent diabetes mellitus.

prominent $\mathrm{U}$ waves with mild ST-segment depression in V4 V6. A chest roentgenogram showed a normal heart size, normal appearance of the lung, and generalized arteriosclerosis. Roentgenographic appearance of the lumbar spine showed relative lucency of the vertebral bodies with the loss of horizontal trabeculae and the indistinctness of vertical trabeculae, wedge deformities, and compression fractures in $\mathrm{T}_{12}$ and $\mathrm{L}_{1}$, indicating the findings of advanced osteoporosis.

Because of hypercortisolemia with eosinopenia, further endocrine and radiological examinations were performed under a 1,200-kilocalorie diet containing $170 \mathrm{mmol}$ sodium/day. A maintenance dose of $22 \mathrm{U}$ human lente insulin was administered daily and no drugs were given at the time of study. Fasting plasma glucose levels were maintained between $8.5-11.2 \mathrm{mmol} /$ $l$ with $\mathrm{HbA}_{1 \mathrm{C}}$ levels of 7.3-8.3\%. Baseline levels of ACTH and corticosteroids are shown in Table 1. Plasma ACTH was low and plasma cortisol was high. Their circadian rhythms were absent. Urinary 17-OHCS and free cortisol excretions were high. Plasma 11-deoxycortisol also was high. Plasma DHEA$\mathrm{S}$ and urinary 17-KS were low to normal. However, the high levels of urinary 17-KS relative to the levels of plasma DHEA$S$ presumably were due to the interference of unknown urinary substances with the urinary 17-KS assay (Zimmermann's reaction). Plasma renin activity was normal. Plasma aldosterone, 18 -OHB and corticosterone were normal and urinary aldosterone was subnormal. As shown in Table 2, overnight single dose
Table 1. Endocrinological Data (1)

\begin{tabular}{lcc}
\hline & Patient & Normal range \\
\hline Plasma ACTH $(\mathrm{pmol} / l)$ & & \\
$0800 \mathrm{~h}$ & $<2$ & $2-13$ \\
$0100 \mathrm{~h}$ & $<2$ & \\
& & \\
Plasma cortisol $(\mu \mathrm{mol} / l)$ & $0.68-1.21$ & $0.14-0.52$ \\
0800 h & $0.63-0.92$ & $0.03-0.30$ \\
0100 h & $4-6$ & $0-2$ \\
Plasma 11-deoxycortisol $(\mathrm{nmol} / l)$ & & \\
& & $0-4 *$ \\
Plasma DHEA-S $(\mu \mathrm{mol} / l)$ & & \\
& & \\
Plasma PRA $\left(\mathrm{ng} \bullet l^{-1} \bullet \mathrm{s}^{-1}\right)$ & $0.11-0.14$ & $0.11-0.42^{*}$ \\
& & \\
Plasma aldosterone $(\mathrm{pmol} / l)$ & $69-83$ & $61-224^{*}$ \\
Plasma 18-OHB $(\mathrm{pmol} / l)$ & 418 & $279-1,116$ \\
Plasma corticosterone $(\mathrm{nmol} / l)$ & 16.8 & $5.8-24.6$ \\
Plasma DOC $(\mathrm{pmol} / l)$ & 181 & $91-909$ \\
Urinary 17-OHCS $(\mu \mathrm{mol} / \mathrm{d})$ & $29.8-44.6$ & $8.3-24.8$ \\
Urinary 17-KS $(\mu \mathrm{mol} / \mathrm{d})$ & $12.6-17.9$ & $3.5-31.5$ \\
Urinary free cortisol $(\mathrm{nmol} / \mathrm{d})$ & $220-541$ & $84-280$ \\
Urinary aldosterone $(\mathrm{nmol} / \mathrm{d})$ & $1-1.4$ & $1-17^{*}$ \\
\hline
\end{tabular}

*age-matched elderly controls. DHEA-S: dehydroepiandrosterone sulphate, 18-OHB: 18-hydroxycorticosterone, DOC: 11-deoxycorticosterone, 17-OHCS: 17-hydroxycorticosteroids, 17-KS: 17ketosteroids.

( $1 \mathrm{mg}$ or $8 \mathrm{mg}$ ) and standard high dose $(8 \mathrm{mg} / \mathrm{day}$ for 2 days) dexamethasone suppression tests resulted in the failure of plasma cortisol and urinary 17-OHCS, respectively, to be suppressed. CRH $(100 \mu \mathrm{g}$ ovine CRH, i.v. $)$ and ACTH $(250 \mu \mathrm{g}$ $\alpha$-ACTH-(1-24), i.v.) tests also revealed no response of plasma ACTH and cortisol, respectively. Computed tomography (CT) scan and magnetic resonance imaging (MRI) of the head and sella turcica showed mild brain atrophy without infarction and no abnormalities of the sella. CT scan and MRI of the abdomen revealed a right adrenal mass with normal appearance in the left side (Fig. 2); there was no evidence of pancreatic, hepatic, intestinal or ovarian tumor. Gamma camera imaging of $900 \mu \mathrm{Ci}$ ${ }^{131}$ I-labeled cholesterol revealed isotopic uptake in the right adrenal gland only.

The patient was treated with diet, human insulin, potassium supplement, trilostane $(240 \mathrm{mg} /$ day $)$ and sedatives for eight months of hospitalization, while she remained bedridden. During that time, the hypokalemic metabolic alkalosis rapidly disappeared, but her body weight remained unchanged. Her blood pressure was normal and the fasting plasma glucose ranged from $8.5-12.3 \mathrm{mmol} / l$. Plasma cortisol slightly decreased to $0.54 \mu \mathrm{mol} / l$ two months after the treatment and then remained at 0.44 to $0.62 \mu \mathrm{mol} / l$. Seven months after admission, the patient suffered from aspiration pneumonia. Despite intensive treatment, the patient's condition continued to deteriorate 
Cushing's Syndrome in the Aged

Table 2. Endocrinological Data (2)

\begin{tabular}{|c|c|c|c|c|c|}
\hline & \multicolumn{5}{|c|}{ Patient } \\
\hline \multicolumn{6}{|c|}{ Dexamethasone (DXM) suppression test } \\
\hline Overnight single dose & Baseline & \multicolumn{2}{|c|}{ DXM $1 \mathrm{mg}$} & \multicolumn{2}{|c|}{ DXM $8 \mathrm{mg}$} \\
\hline Plasma cortisol $(\mu \mathrm{mol} / l)$ & $0.80,1.08$ & \multicolumn{2}{|c|}{0.60} & \multicolumn{2}{|c|}{0.69} \\
\hline Standard high dose & Baseline & \multicolumn{2}{|c|}{ DXM $8 \mathrm{mg} /$ day } & \multicolumn{2}{|c|}{ DXM $8 \mathrm{mg} /$ day } \\
\hline Urinary 17-OHCS $(\mu \mathrm{mol} / \mathrm{d})$ & 13.5 & \multirow{2}{*}{\multicolumn{2}{|c|}{$\begin{array}{l}12.3 \\
17.5\end{array}$}} & & 2.7 \\
\hline Urinary 17-KS $(\mu \mathrm{mol} / \mathrm{d})$ & 17.9 & & & \multicolumn{2}{|c|}{13.0} \\
\hline CRH test & 0 & $15^{\prime}$ & 30 ' & 45 & 60 \\
\hline Plasma ACTH $(\mathrm{pmol} / l)$ & $<2.2$ & $<2.2$ & $<2.2$ & 2.4 & $<2.2$ \\
\hline Plasma cortisol $(\mu \mathrm{mol} / \mathrm{d})$ & 1.05 & 0.90 & 1.06 & 1.07 & 1.15 \\
\hline Rapid ACTH test & 0 & & 30 ' & & 60 \\
\hline Plasma cortisol $(\mu \mathrm{mol} / l)$ & 0.83 & & 0.94 & & 0.92 \\
\hline Plasma aldosterone $(\mathrm{nmol} / l)$ & 0.07 & & 0.12 & & 0.10 \\
\hline
\end{tabular}

17-OHCS: 17-hydroxycorticosteroids, 17-KS: 17-ketosteroids.

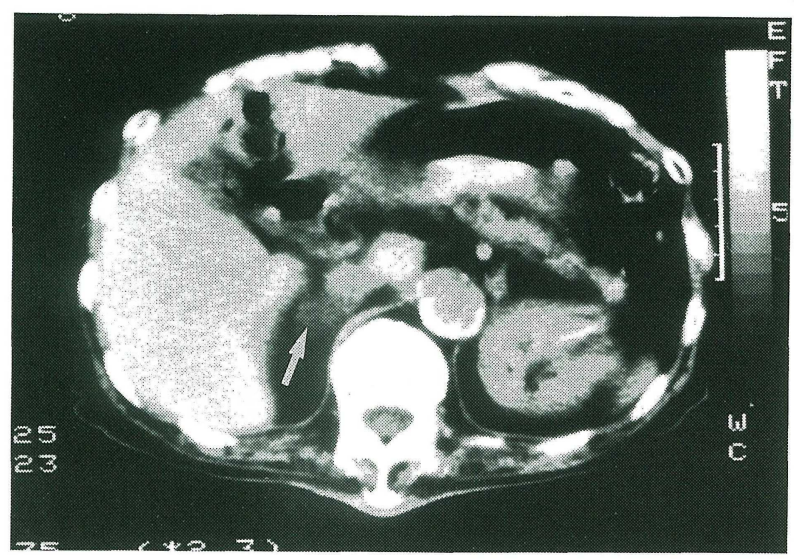

Figure 2. The CT scan of a right adrenal mass in an aged woman with non-insulin-dependent diabetes mellitus.

and she died. Autopsy findings showed aspiration pneumonia in the left lung, arteriosclerotic changes, and atrophic brain (1,060 g) with no infarction. The pituitary weighed $300 \mathrm{mg}$ and showed no tumorous or hyperplastic foci. Prominent Crooke's hyaline changes, however, were present in the anterior lobe of pituitary gland (Fig. 3A). The right adrenal contained a right adrenal tumor $(2.1 \times 1.7 \mathrm{~cm}$ and weight $11.6 \mathrm{~g})$ (Fig. 3B); the left adrenal gland weighed $6.2 \mathrm{~g}$. The adrenal tumor showed histologically a well encapsulated, benign adrenal adenoma consisting of mixtures of clear cells and in part compact cells. The remaining adrenal glands were somewhat atrophic.

\section{Discussion}

We describe non-obese Cushing's syndrome which developed in an aged diabetic woman. She had a 16-year history of
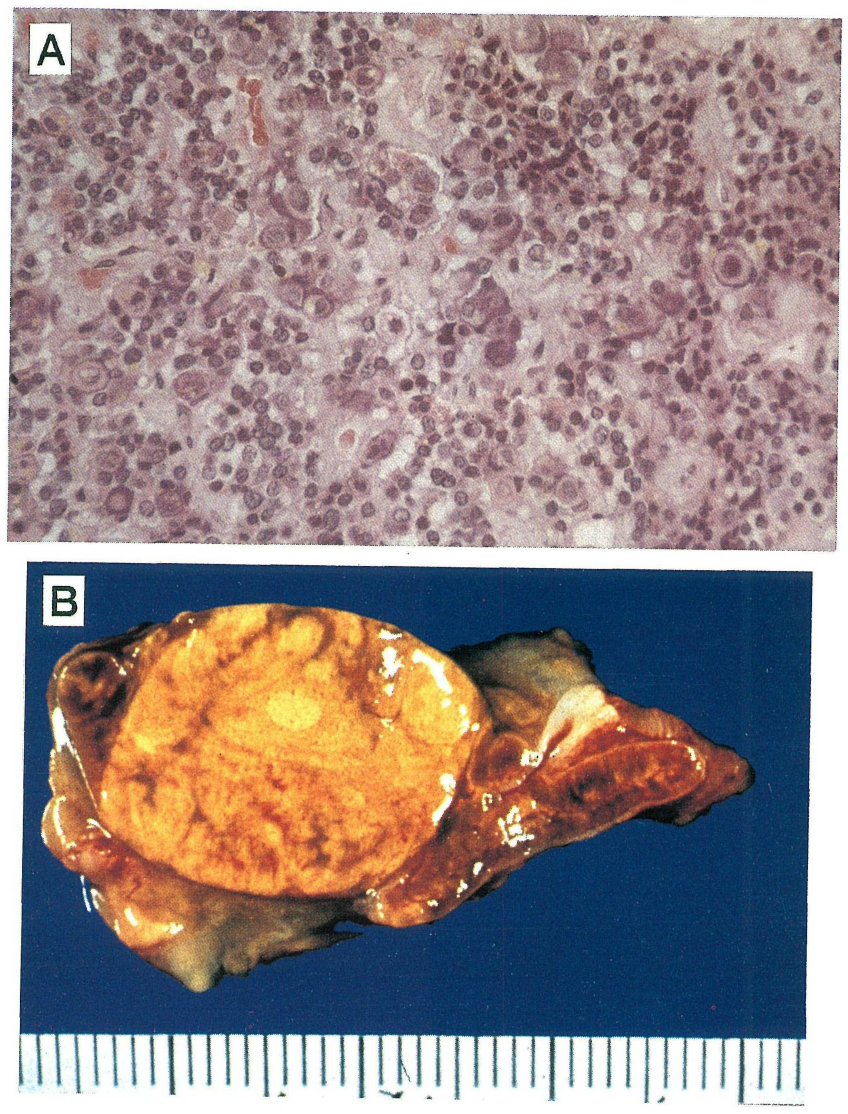

Figure 3. A) Histological findings in the anterior lobe of pituitary gland (HE stain, $\times \mathbf{4 0 0}$ ). B) Adrenocortical adenoma showing the cut surface.

NIDDM with no obesity and mild hypertension, and presented with a slight weight loss during the previous 3 weeks after 
sustaining a fall. On admission, Cushing's syndrome was suspected because of hypercortisolemia with abnormal white blood cell differentiation, especially eosinopenia $(3,4)$. Radiological examinations revealed a right adrenal mass with no abnormalities of the sella turcica. Further endocrine examinations including overnight single low- and high-dose dexamethasone suppression tests $(5,6)$ and a standard high-dose dexamethasone suppression test indicated the presence of Cushing's syndrome due to an adrenal mass. On autopsy, the adrenal mass was histologically confirmed to be an adrenocortical adenoma.

In Cushing's syndrome, progressive obesity, of characteristic fat distribution, is the commonest sign, but it is not pathognomonic $(1,2)$. Strict management with a reducing diet and exercise (2) and association of anorexia nervosa (7) have been reported to minimize the obesity during the illness. Non-obese Cushing's disease has been reported in an aged man with intraventricular hemorrhage and tuberculous peritonitis (8). Our aged woman had a history of non-obese NIDDM and mild hypertension, and experienced the last two or three years' poorness of glycemic control with glibenclamide during the course of NIDDM. Since patients with untreated Cushing's syndrome are generally known to have a life expectancy of 310 years, on average 5 years, and the major cause of death is hypertension and its complication (9), the onset of Cushing's syndrome in our patient presumably was two to three years before diagnosis. The recent difficulty of glycemic control in this patient perhaps resulted from progression of insulin deficiency, and enhanced gluconeogenesis and pronounced insulin resistance by coexisting hypercortisolism (10). Thus, the lack of weight gain in this patient may be chiefly due to the urinary loss of nutrients secondary to hyperglycemia and the appetite loss with aging. Psychological changes, thin skin, muscle weakness and osteoporosis, while common in Cushing's syndrome, also may occur in the NIDDM of an advanced age. Hypertension remained mild during the illness. Although hypokalemic alkalosis is less common in Cushing's syndrome other than ectopic Cushing's syndrome (11), it was observed in this patient. This may be due to the osmotic diuresis secondary to glucosuria and the age-related decrease of food intake in addition to an enhanced mineralocorticoid action of cortisol at the renal tubule $(12,13)$. The hypokalemia may further aggravate the muscle weakness. Thus, many of the common features of Cushing's syndrome in this patient may have been concealed by mental, physical and metabolic alterations with both aging itself and the coexisting diabetes mellitus.
Although hypercortisolism without the clinical features of Cushing's syndrome also suggests glucocorticoid resistance (14), this seems unlikely in this patient because of the absence of circadian rhythms of plasma cortisol and ACTH. The presence of glucocorticoid resistance to adipocytes, however, was not determined in this patient.

In conclusion, this case demonstrates that aging and coexisting diabetes mellitus can conceal the common features of Cushing's syndrome. In this patient, hypercortisolemia with eosinopenia helped to suspect Cushing's syndrome and prompted further diagnostic investigations.

\section{References}

1) Ross EJ, Linch DC. Cushing's syndrome-killing disease: discriminatory value of signs and symptoms aiding early diagnosis. Lancet 2: 646, 1982.

2) Orth DN, Kovacs WJ, DeBold CR. The adrenal cortex. in: Williams Textbook of Endocrinology, Wilson JD, Foster DW, Eds. WB Saunders, Philadelphia, 1992, p.489.

3) Plotz CM, Knowlton AI, Ragan C. The natural history of Cushing's syndrome. Am J Med 13: 597, 1952.

4) Ross EJ, Marshall-Jones P, Friedman M. Cushing's syndrome: diagnostic criteria. Q J Med 35: 149, 1966.

5) Bruno OD, Rossi MA, Contreras LN, et al. Nocturnal high-dose dexamethasone suppression test in the aetiological diagnosis of Cushing's syndrome. Acta Endocrinol (Copenh) 109: 158, 1985.

6) Tyrrell JB, Finding JW, Aron DC, Fitzgerald PA, Forsham PH. An overnight high-dose dexamethasone suppression test for rapid differential diagnosis of Cushing's syndrome. Ann Intern Med 104: 180, 1986.

7) Black MM, Hall R, Kay DWK, Kilborn JR. Anorexia nervosa in Cushing's syndrome. J Clin Endocrinol Metab 25: 1030, 1965.

8) Tsubota A, Shishiba Y, Shimizu T, Ozawa Y, Sawano S, Yamada S. Masked Cushing's disease in an aged man associated with intraventricular hemorrhage and tuberculous peritonitis. Jpn J Med 30: 233, 1991.

9) Labhart A. Adrenal cortex. in: Clinical Endocrinology, Theory and Practice, Labhart A, Ed. Springer-Verlag, Berlin, 1986, p.349.

10) Yasuda K, Hines E, Kitabuchi AE. Hypercortisolism and insulin resistance. Comparative effects of prednisolone, hydrocortisone, and dexamethasone on insulin binding of human erythrocytes. J Clin Endocrinol Metab 55: 910, 1982.

11) Howlett TA, Druury PL, Perry L, Doniah I, Rees LH, Besser GM. Diagnosis and management of ACTH-dependent Cushing's syndrome; comparison of the features in ectopic and pituitary ACTH production. Clin Endocrinol 24: 699, 1986.

12) Christy NP, Laragh JH. Pathogenesis of hypokalemic alkalosis in Cushing's syndrome. N Engl J Med 265: 1083, 1961.

13) Schambelan M, Slaton PE, Biglieri EG. Mineralocorticoid production in hyperadrenocorticism. Role in pathogenesis of hypokalemic alkalosis. Am J Med 51: 299, 1971.

14) Javier EC, Reardon GE, Malchoff CD. Glucocorticoid resistance and its clinical presentations. Endocrinologist 1: 141, 1991. 